\title{
A Configurational Analysis of Ethnic Protest in Europe
}

Citation for published version (APA):

Cebotari, V., \& Vink, M. (2013). A Configurational Analysis of Ethnic Protest in Europe. International Journal of Comparative Sociology, 54(4), 298-324. https://doi.org/10.1177/0020715213508567

Document status and date:

Published: 01/08/2013

DOI:

10.1177/0020715213508567

Document Version:

Publisher's PDF, also known as Version of record

Document license:

Taverne

\section{Please check the document version of this publication:}

- A submitted manuscript is the version of the article upon submission and before peer-review. There can be important differences between the submitted version and the official published version of record.

People interested in the research are advised to contact the author for the final version of the publication, or visit the DOI to the publisher's website.

- The final author version and the galley proof are versions of the publication after peer review.

- The final published version features the final layout of the paper including the volume, issue and page numbers.

Link to publication

\footnotetext{
General rights rights.

- You may freely distribute the URL identifying the publication in the public portal. please follow below link for the End User Agreement:

www.umlib.nl/taverne-license

Take down policy

If you believe that this document breaches copyright please contact us at:

repository@maastrichtuniversity.nl

providing details and we will investigate your claim.
}

Copyright and moral rights for the publications made accessible in the public portal are retained by the authors and/or other copyright owners and it is a condition of accessing publications that users recognise and abide by the legal requirements associated with these

- Users may download and print one copy of any publication from the public portal for the purpose of private study or research.

- You may not further distribute the material or use it for any profit-making activity or commercial gain

If the publication is distributed under the terms of Article $25 \mathrm{fa}$ of the Dutch Copyright Act, indicated by the "Taverne" license above, 


\title{
A configurational analysis of ethnic protest in Europe
}

\author{
Victor Cebotari

\section{Maarten P Vink} \\ Maastricht University, The Netherlands; European University Institute, Italy
}

Maastricht University, The Netherlands; Centre for Population, Poverty and Public Policy Studies, Luxembourg

\begin{abstract}
This article analyzes the conditions under which ethnic minorities intensify or moderate their protest behavior. While this question has been previously asked, we find that prior studies tend to generalize explanations across a varied set of ethnic groups and assume that causal conditions can independently explain whether groups are more or less mobilized. By contrast, this study employs a technique - fuzzy-set analysis - that is geared toward matching comparable groups to specific analytical configurations of causal factors to explain the choice for strong and weak protest. The analysis draws on a sample of 29 ethnic minorities in Europe and uses three group and two contextual conditions inspired by Gurr's ethnopolitical conflict model to understand why some ethnic minorities protest more frequently than others. We find that two grouprelated factors have the strongest claim to being generalizable: while territorial concentration is a necessary condition for strong protest, national pride is a necessary condition for weak protest. The contextual factors of level of democracy and ethnic fractionalization, which are often emphasized in the literature, and the perceived political discrimination of a group, are neither necessary nor individually sufficient conditions for either strong or weak protest. Hence, they help understanding some cases, but not all, and only in combination with other conditions. Such causal complexity, inherent in the phenomenon of ethnic protest, underscores the need for a case-sensitive, yet comparative, approach.
\end{abstract}

\section{Keywords}

Causal complexity, ethnic protest, Europe, fuzzy-set analysis, minorities at risk

\section{Introduction}

Ethnic diversity and its resulting dynamics, such as ethnic contention in its various forms, have been issues of constant academic interest in recent decades. It is a common belief in the literature that ethnic diversity poses a substantial risk to social stability in any country (Gurr, 1996; Horowitz, 2000; Huntington, 1996). In Europe, the powerful force of ethnic diversity was at work for

\section{Corresponding author:}

Victor Cebotari, Maastricht Graduate School of Governance, Maastricht University, Keizer Karelplein I9, Maastricht 62 II TC, The Netherlands.

Emails: victor.cebotari@maastrichtuniversity.nl; victor.cebotari@ceps.lu 
centuries, molding conflicts and ethnic movements. More recently, the collapse of communism and the formation of new democratic regimes in Eastern Europe unlocked a reservoir of ethnic potential and opened a wide range of opportunities for ethnic movements to manifest. In Europe, ethnic movements are mostly peaceful, with violence as an exception rather than a common trend. In fact, empirical evidence suggests a global shift in mobilization behavior from violent rebellion to peaceful protest (Gurr, 2000). This evidence coincides with one of the long-standing predictions in the literature that while ethnic movements will decrease (Dogan, 1994), peaceful contention will increase as part of a deep-rooted intergenerational change in both individual and societal behavior (Barnes et al., 1979; Inglehart, 1990; Inglehart and Catterberg, 2002). As a result, an increase in peaceful contention should be viewed as 'an extension of the political repertory of democratic citizens' (Kaase, 2010) to peacefully accommodate the challenging demands of ethnic diversity.

Despite the wider phenomenon of protest mobilization, it is striking that most of the attention in the current literature continues to analyze ethnic violence. Compared with the current scholarship on ethnic violence, the literature on protest mobilization is rare and unsystematic (Heymann, 1992; Koopmans, 1993; Martin, 1994; Olzak, 1998). Some theorists combine the study of protest and violent contention to produce indexed measures in analyzing joint patterns of mobilization of ethnic groups (Benson and Saxton, 2010; Davenport, 1995; Gurr, 1989; Muller, 1979; Saxton and Benson, 2006). Yet, when targeting mobilization behavior, a choice pattern must be underlined: protest and rebellion must be viewed as 'one strategic choice among others in the decision to mobilize' (McAdam et al., 1996: 17). According to this idea, ceteris paribus, protest is seen as a strategic option by ethnic groups that is of a different intensity than violence and that has an established scope to obtain the desired outcomes given specific configurations of existing conditions at a given time.

This analysis looks at the protest actions of 29 ethnic minority groups in Europe from 1991 to 2003. Europe is characterized by a high degree of ethnic diversity, which originates in complex ethnic settings that allowed different nations to intermingle and to transform across time. The occurring ethnic dynamics were often accompanied by conflict, frequent border changes, assimilation and integration processes. With the increasing democratic standards in the region, many of the ethnic grievances previously solved in a violent manner are currently brought into the political arena where ethnic movements are set to peacefully promote minorities' interests. Although protest is an available choice for politically organized ethnic groups, not all of them choose to mobilize in pursuing their group demands. Thus, there is a legitimate question of why some politically organized groups protest while others do not. The choice for protest mobilization is rarely influenced by a single condition; it is usually a configuration of conditions that provide the proper context in which minority groups mobilize. This article examines the configurational nature of protest mobilization by analyzing the necessary and sufficient conditions, or combinations of conditions, for the weak and strong political mobilization of ethnic groups.

This article applies fuzzy-set analysis, which is part of an emerging methodology called Qualitative Comparative Analysis (QCA) (Ragin, 1987, 2008). This approach allows us to investigate how a number of conditions interact in determining the degree to which ethnic minority groups engage in strong or moderate protest. QCA formalizes case-oriented analysis with a focus on identifying necessary and sufficient conditions that define the context of a particular outcome (for an introduction, see Rihoux and Ragin, 2009; Schneider and Wagemann, 2010). Fuzzy-set analysis is geared toward modeling small or medium-sized datasets of 10-50 cases (for a discussion of the potential and the advantages of QCA and fuzzy-set analysis, see Rihoux, 2006; Vis, 2012).

While fuzzy-set analysis is particularly suited for macro- and group-level analyses, its use in the field of ethnic contention is almost non-existent (see Ragin, 2000: 273-278, for an illustration of 
the advantages of using fuzzy-set in the analysis of protest mobilization). This study contributes to the literature in three ways. First, the analysis adds to existing scholarship by conducting a study of European minorities from both East and West, which display more peaceful mobilization trends than violent conflict, which was more intensively researched. Second, we employ a new methodological approach oriented toward exploring the configurational effects of five group and contextual conditions on the two poles of ethnic protest: strong and weak protest mobilization. In so doing, we reveal evidence from a new empirical angle, which differs from the existing statistical and casestudy approaches. Third, the analysis bridges different approaches in the literature with a comprehensive theoretical framework for the study of ethnic protest, which combines various traditional factors in explaining ethnic contention: the level of democracy, the degree of ethnic fractionalization of a country, the degree of political discrimination, territorial concentration, and the sense of national pride among members of the minority group.

The first section of this article presents the theoretical framework from which the hypotheses are derived. Subsequently, the following section presents the operationalization of the conditions and the fuzzy-set methodology employed in this study. The next section presents the main findings, including the analysis of necessity and sufficiency for strong and weak protest. This study concludes with some reflections and implications of the current study and for future research.

\section{A theory of protest mobilization}

The existing literature in the area of ethnicity and conflict is abundant and comprises studies of ethnopolitical, elite, and nationalist behavior. The scholarship on the political configuration of the nationalist demands pertains to voting and campaign activities, non-violent social protest, and violent unrest. The conflict resulting from ethnopolitical dynamics was previously analyzed from the angle of intensity that protest or rebellion may take. With the availability of large-scale quantitative data, the literature concentrated on observing the likelihood of moving up the ladder of ethnic contention: from no actions of conflict to mobilized actions of conflict, from protest to rebellion, or from low-intensity to high-intensity unrest. Alternatively, the qualitative literature on nationalism and ethnopolitical behavior focused on specific, context-oriented case studies of violent or non-violent contention. So far, no coherent theory-making approached ethnic mobilization in its configurational nature, where both strong and weak actions of unrest are simultaneously explained by various combinations of interacting conditions. This study tries to fill this gap.

This article brings together two threads of literature with a somewhat different take on protest mobilization. First, we find the 'ethnopolitical conflict' literature, which aims to understand the dynamics of peaceful and violent mobilization at the ethnic group level (Gurr, 1993a, 1993b, 1994, 2000). This stream of literature has three distinct but often interlinked analytical components: one cluster of studies approaches protest as an independent non-violent form of expressing ethnopolitical demands (DeNardo, 1985; Gurr, 1989; Heymann, 1992; Olzak, 1998); another cluster of research looks into violent means of ethnopolitical conflict such as rebellion, terrorist actions, or civil wars (Cederman et al., 2011; Cederman and Girardin, 2005; Cunningham, 2011; Fearon and Laitin, 2003; Gurr and Moore, 1997; Ward et al., 2010); while a third cluster of scholars attempts to merge and analyze violent and non-violent unrest as a single, multi-level intensity scale of conflict mobilization (Benson and Rochon, 2004; Benson and Saxton, 2010; Davenport, 1995; Muller, 1979; Saxton and Benson, 2006).

The second stream of literature is more sociologically oriented, where the theoretical foundation for protest is sought not so much through ethnopolitics, but rather in the inter-personal dynamics of political participation (Almond and Verba, 1989 [1963]; Catterberg, 2003; Gherghina and Jiglau, 2011; Inglehart and Catterberg, 2002; Koopmans, 1993; Sandovici and Listhaug, 2010; 
Tilly, 1978). Initially, studies on political participation focused on voting and party activities with limited or no inclusion of the ethnic component (Berelson et al., 1954). Starting with Almond and Verba (1989 [1963]), the concept of political participation was broadened to include communal activities, which have the potential for the inclusion of ethnic movements. All actions of political participation that take place via the institutionalized paths of campaign and non-campaign communal activities are classified as conventional protest. In contrast, the non-institutionalized protest such as mass demonstrations, petitioning, and violent mayhem are labeled as unconventional (Barnes et al., 1979) or 'elite challenging' (Marsh, 1990) actions of political participation. Currently, the 'conventional' and 'unconventional' denominations are increasingly contested by scholars with certain unconventional acts of political participation influencing the decision-making process (Stolle and Hooghe, 2011).

This study bridges the gap between the two strands of the literature by linking the theoretical streams of peaceful ethnopolitical conflict and actions of political participation. The conceptual framework that permits such a link is the notion of contentious politics, defined as 'collective activities on the part of claimants - or those who claim to represent them - relying at least in part on non-institutional forms of interaction with elites, opponents or the state' (Tarrow, 1996: 874). According to this concept, there is practically no discontinuity between ethnopolitical actions of protest and institutional or non-institutional forms of political participation. Hence, we view protest mobilization as a non-violent form of contentious politics. This definition includes peaceful actions of mobilization at the ethnic group level, directed against the dominant ruling authority in the state and with an aim to protect and enhance the interests of the mobilized ethnic community. In so doing, the range of protest activities may vary in intensity from verbal opposition and symbolic resistance to large-scale demonstrations and actions of peaceful unrest.

The time frame of the analysis is from 1991 to 2003. In Europe, this period coincides with significant ethnic dynamics following the end of the East-West ideological divide. These dynamics mark a significant shift in ethnic activism from violent rebellion to more peaceful protest (Gurr, 2000: xiii). The change toward more peaceful protest is due to an increased attention on policies of recognition and the integration of ethnic minorities (Gurr, 2000: xiv). This process makes multiculturalists believe that the border between assimilation and integration of ethnic diversity is disappearing in many European countries (Modood, 2005: 5). In general, non-violent mobilization means are preferred by ethnic groups for two well-documented reasons (Fox, 2003; Gurr, 2000). First, peaceful protest is more likely to encourage the decision-making authority to negotiate grievances and group demands. Second, ethnic groups prefer peaceful mobilization as long as they are confident that societal dialogue will reach the target authority and result in positive outcomes.

\section{Accounting for collective actions of ethnic contention}

While the literature on ethnic mobilization includes a wide variety of factors that are linked to protest, the theoretical framework of this analysis is based on five conditions that reflect the predominant model in explaining contentious politics as developed by Gurr (1993a, 2000). Specifically, Gurr indicates that both peaceful and violent contention are more likely to develop alongside several risk factors, including opportunity, capacity, incentive, and values of identity. Group actions depend on contextual opportunity factors, such as the character of the state, that influence the choice and mobilization strategies of ethnic groups. The capacity of ethnic groups for collective action relies on the strength of the group or the supra-group identities, as well as on grievances that provide the right incentive for mobilization. Simply put, a number of contextual and group conditions come together to shape human action. Hence, collective mobilization is assumed to be configurational, where an independent factor rarely leads fully to the presence or the absence of ethnic 
contention. Yet, independently treating the impact of each condition on conflict, as is usually done in the literature, restricts the measure of complexity that Gurr's (1993a, 2000) theoretical model assumes. This article assumes that the configuration between the opportunity, incentive, capacity, and identity conditions produces causal dynamics that increase or moderate the intensity of ethnopolitical contention. We now introduce the five conditions that relate to these factors outlined by Gurr and discuss how their presence and absence can be linked set-theoretically (focusing on necessary and sufficient conditions) to strong and weak political protest among ethnic groups. The measurement of these conditions is then discussed in the next section.

Level of democracy: The context of opportunity. The literature underlines the influence that contextual opportunity structures have on the timing and strategic choice of the intensity of unrest (Benson and Saxton, 2010; Gleditsch and Ruggeri, 2010). The level of institutionalized democracy is mentioned as a key characteristic of the state in determining group opportunities to engage in contentious actions (Gleditsch and Ruggeri, 2010; Gurr, 1993a, 1993b; Kaase, 2010; Marshall and Gurr, 2003; Martin, 1994). Previous studies found that strong democratic environments have a positive effect on decreasing violent tendencies of potentially rebellious ethnic groups (Davenport, 1995, 1999; Gurr, 1993a; Gurr and Moore, 1997). The argument is based on the idea that democratic states have the necessary instruments to manage pluralism peacefully and therefore rarely rely on coercive means for managing ethnic disputes. Especially in durable democratic regimes, claims-making is naturally channeled toward non-violent forms of ethnic contention. Conversely, the decrease in democratic standards associated with regime change, albeit transient, was found to increase the opportunity for more intense, if not more violent, contention (Horowitz, 1993; Olzak and Tsutsui, 1998; Posen, 1993; Saideman et al., 2002; Snyder, 1999). The opportunity for protest is high at the time of transition because it produces institutional chaos, which is viewed by ethnic elites as the proper environment to push for more ethnic demands (Horowitz, 2000). Taking into account the reasons presented above, it is expected that strong democracies would accommodate protest actions by means of decreasing the contextual opportunity for violent mobilization. At the same time, the absence of a democratic context is expected to serve as an opportunity for protest if the claims-makers perceive it as the proper juncture to advance their demands. Because a relatively high level of democracy may thus be hypothetically linked to both weak and strong protest, it is unlikely that level of democracy is a necessary condition for protest mobilization. Rather, we expect that the level of democracy is part of a more complex configuration of sufficient conditions linked to the presence or absence of strong protest. In particular, we see democracy level as Insufficient but Non-redundant part of a condition which is itself Unnecessary but Sufficient for the occurrence of the effect (INUS) Mackie (1980). We come back to this aspect in our analysis.

Ethnic fractionalization:Accounting for ethnic diversity. The degree of ethnic diversity in a country is seen in the literature as a key predictor for ethnic contention. This study employs ethnic fractionalization as a measure of ethnic diversity (Fearon and Laitin, 2003). Ethnic fractionalization reveals the degree to which ethnic units divide the national population of a particular state. Research points to the fact that ethnically fractionalized societies are more likely to experience instability and contention (Alesina et al., 2003; Cederman et al., 2010; Cederman and Girardin, 2005; Fearon and Laitin, 2003). We thus expect strong ethnic fractionalization to be a sufficient condition for strong protest and weak ethnic fractionalization to be a sufficient condition for weak protest. However, based on the literature, we do not expect this condition to be a necessary condition for weak or strong protest; after all, strong or weak protest is generally not seen to depend solely on ethnic fractionalization. 
Territorial concentration:The capacity to protest. When the ethnic factor is linked to a specific territorial location, it provides capacity to become mobilized (Gurr, 1993b, 2000). Scholars found that territorially concentrated minorities are more likely to start ethnic strikes, whereas the dispersed, especially urban, minorities are the least predisposed to unrest (Posen, 1993; Toft, 2001, 2003). The same studies further note that countries with more than two regionally compact minorities are more likely to experience ethnic contention. More recent data and follow-up studies validated previous findings and confirmed the argument that there is a strong link between territorial concentration and more ethnic unrest (Weidmann, 2009; Weidmann et al., 2010).

Stronger mobilization capacity comes from the fact that territorially compressed minorities have better intra-group communication and stronger feelings of in-group 'we' identity. At the same time, territorial concentration weakens the out-group, national identity and creates interethnic frictions (Korostelina, 2004). Either way, it is easier for territorial ethnies to mobilize in accommodating their group demands. Given the unequivocal opinion among scholars that strong contention is likely present in ethnic-compact territorial units, we hypothesize that this condition is sufficient, if not necessary, for strong protest. In a symmetrical view, we expect that a dispersed territorial status is a sufficient condition for weak protest. Yet, a weak territorial concentration is unlikely a necessary condition for weak protest, as it does not provide a compelling reason of why ethnic groups do not mobilize strongly.

Political discrimination:The incentive for protest. Any form of discrimination incites protest. The collective disadvantages resulting from political circumstances lead to grievances and conflict (Gurr, 2000). Previous studies reveal that ethnic groups are more likely to mobilize when their political status is threatened by the ruling authority (Cederman et al., 2010; Gurr, 1993a, 1993b; Gurr and Moore, 1997; Walter, 2006). Furthermore, ethnic groups feel deprived when their political representation is lower than that of other groups in the country. In this case, they blame the state for their status and perceive the discrimination as an act of political injustice (Horowitz, 2000; Marshall and Gurr, 2003). The context of the state (i.e. the level of democracy and ethnic fractionalization) is thus configurationally important in modeling the degree of political discrimination leading to contention. In other words, we expect political discrimination be an INUS condition.

National pride: The cohesive force of identity. National pride is a form of national attachment that boosts the desire for interethnic cohesion. Gurr (1993a, 1993b) posits that ethnic groups with the highest likelihood for protest are those with the most cohesive identities. However, instead of focusing on the frequently used group-level identities, this study considers feelings of national pride that reflect the positive esteem that individuals feel toward their country (Smith and Jarkko, 1998: 3). National pride is one of the most coherent measurements for national identity (Smith and Jarkko, 1998) and an important condition to use when studying the desire for mobilization in heterogeneous ethnic environments.

The international community is primarily represented by nation-states, in which ethnic politics evolve around one dominant nationality. Thus, national identity and the resulting national pride are values that hold nation-states together and shape the relationships between different ethnic communities. A number of sociologists and political psychologists conducted research linking feelings of national identity and nationalist behavior (Gaertner et al., 1999; Guibernau, 2006; Huddy and Khatib, 2007; Korostelina, 2004; Mansbach and Rhodes, 2007; Tiryakian, 2004). They found that in most cases, national identity moderates the effects of ethnic identity, and subsequently, the desire for ethnic mobilization. In some instances, however, national identity does not lead to national unity. There are instances when ethnic groups use loyalty to the nation solely to promote their community goals and receive additional benefits from the state (Korostelina, 2004). 
Given the strong causal link to interethnic cohesion, a strong value of national pride would imply the absence of strong contention, both on the sufficient and necessary sides. On the contrary, weak values of national pride are expected to weaken national unity and provide a sufficient boost for strong protest. Yet, as there is not a persuasive theoretical evidence to link strong protest with weak national pride, we do not expect this relationship to be a necessary one.

\section{Research design}

\section{Defining ethnicity and ethnic groups}

The analytical units of this study are ethnic groups. Before presenting the sampling procedure, the concept of ethnic group, also known as “subnations' (Ragin, 1989: 133), must be explained. Ethnie refers to a set of characteristics defining one group from another (Smith, 1986: 26-28). Ethnic characteristics are seen as primordial objects such as biological traits, religion, language, territory, and so on, and it is often argued that they are powerful conditions leading to conflict (Grosby, 1994; Horowitz, 2000, 2004; McKay, 1982).

Alternatively, an ethnic community is seen as a social construction that shares a collective identity built on the characteristics of ethnicity (Weber, [1922] 1978). In Gurr's (1993a: 5) view, ethnicity and ethnic groups are continuously evolving and adapting social realms. The evolutionary process attached to ethnic groups often entails political mobilization to promote and improve their social status. Drawing on these insights, it is maintained in this study that ethnic groups are structural entities formed and preserved by both primordial features acquired at birth and by social characteristics coming with the development of multicultural societies. The essence of this statement represents the working definition of ethnic groups employed in this study.

\section{The sample}

The sample includes 29 ethnic minorities from 16 European countries (see Appendix 1 Table 5 for a complete overview). These groups were selected on the basis of the following five criteria.

First, we only include groups that are 'at risk' of discriminatory treatment in relation to other group(s) in the country (either minority or majority). According to the Minorities at Risk (MAR) project (2005), an ethnic group is considered 'at risk' when it is the subject of systematic discriminatory treatment for at least 5 years in a row, is communally organized, and collectively mobilizes to defend and promote its self-defined interests. In other words, the sample includes only disadvantaged minorities that are, at least, minimally politically mobilized. This criterion provides an ideal testing ground for this study because we are interested in uncovering what conditions lead to strong and weak protest given the same 'at risk' pressure for mobilization among all ethnic groups in the sample. Second, as the focus in this study is on traditional ethnic communities with a long-standing historical presence in a specific country, the sample excludes immigrant groups even if they fulfill the 'at risk' criteria established by MAR. Third, the country in which the ethnic group resides must have a population exceeding 500,000 with significant minorities in its territory. A significant minority has at least 100,000 members or represents at least 1 percent of the country's total population. Fourth, we include ethnic minorities only from countries that are ordinarily considered to be part of the geographical Europe, understood in a broad sense to include also the Caucasian states of Azerbaijan and Georgia. Despite having part of their land-masses within Europe, we exclude Russia and Turkey as the greater part of their territory is normally considered to be within geographical Asia. The inclusion of these two states would bring in many additional ethnic groups and mobilization contexts which would stretch the comparability of the groups included in the analysis. 
Finally, a pragmatic criterion was employed to keep only those ethnic groups for whom grouplevel data on national pride values are available from the European Value Survey (EVS) (see section 'Data and calibration'). ${ }^{1}$

\section{Fuzzy-set analysis and configurational logic}

This study employs fuzzy-set analysis, which is based on the seminal work of Charles Ragin (1987, 2000, 2008) and is part of a broader family of techniques called QCA. QCA is geared toward capturing the configurational nature of social phenomena and in our view is particularly suitable for analyzing complex events such as ethnic contention. However, notwithstanding its increasing use in comparative social science (Marx et al., 2013), QCA did not fully outgrow its relative novelty. Certainly, in the field of ethnopolitical mobilization, the dominant approaches are still large- $\mathrm{N}$ statistical analysis and single-case studies or focused comparisons of a few cases. These traditional quantitative and qualitative approaches contribute enormously to a rich and abundant literature, yet to some extent also reinforce the somewhat artificial distinction between case- and variableoriented research. As a result, many studies focus on the causal relevance of independent variables across a large set of rather anonymous cases and many case studies highlight causal mechanisms in one or a few cases. At the same time, there are limited studies that aim to combine comparative analysis with a case-oriented approach.

Whereas traditional quantitative analysis - still the predominant form of comparative analysis in this research domain - is often focused on detecting empirical relevance of 'independent' variables, fuzzy-set analysis makes no such assumption of independence. If anything, fuzzy-set analysis assumes conjunctural causation and aims to analyze whether individual conditions operate alone or work in conjunction with one another related to the presence or absence of the outcome. Moreover, statistical methods focus predominantly on variables and pay little attention to the empirical diversity of the cases included in the analysis. By contrast, QCA allows for a caseoriented approach, where good case knowledge is mandatory to explain the link between the theory, the cases, and the obtained findings.

A fuzzy-set is a '[...] a fine-grained, [pseudo] continuous measure that has been carefully calibrated using substantive and theoretical knowledge relevant to set membership' (Ragin, 2000: 7). Fuzzy-set analysis thus avoids the pitfalls of the previous dichotomous Boolean approach by 'calibrat[ing] partial membership scores in sets using values in the interval between [0] (nonmembership) and [1] (full membership) without abandoning core set theoretic principles such as, for example, the subset relation' (Ragin, 1989: 88).

Fuzzy-set analysis revolves around the analysis of subset relations, particularly the configuration of necessary and sufficient conditions leading to a specific outcome. In the analysis of necessity, the outcome is a subset of the condition - that is, the condition has to be present for an outcome to occur (Braumoeller and Goertz, 2000). Hence, this means that for a necessary condition (where the outcome is a subset of the condition), the fuzzy score on the outcome for each case should be lower or equal to the fuzzy score on the necessary condition $\left(\mathrm{Y}_{\mathrm{i}} \leq \mathrm{X}_{\mathrm{i}}\right)$. Inversely, for a sufficiency relation (where the condition is a subset of the outcome), the fuzzy scores on the condition should be lower or equal to the fuzzy scores on the outcome $\left(\mathrm{X}_{\mathrm{i}} \leq \mathrm{Y}_{\mathrm{i}}\right)$.

Because we find, at best, approximations of subset relations in fuzzy-set analysis, given that cases can have membership in a set and its negation, fuzzy-set QCA (fsQCA) uses a parameter of fit called 'consistency' to indicate the degree to which the subset relation is approximated (Ragin, 2006). This measure ranges from 0 to 1 , with 1 indicating a perfect subset relation. While there are no absolute standards to set the benchmark for consistent subset relations, generally a consistency score of .80 is seen as the minimum cutoff point for a reliable analysis of sufficiency (Ragin, 2009: 
121; Schneider and Wagemann, 2012: 127). The benchmark for consistency is normally set higher when analyzing necessary conditions to reduce the likelihood of true logical contradictions (e.g. Schneider and Wagemann, 2012: 139-143; see also, 221-232, on hidden and false necessary conditions).

A second important parameter of fit in fuzzy-set analysis is the score of 'coverage', which indicates the relation in size between the condition set and the outcome set. In other words, coverage 'gauges empirical relevance or importance' of conditions to the outcome (Ragin, 2006: 292). For a sufficient condition, coverage reveals the proportion of cases that are covered by the sufficient condition. For a necessary condition, coverage is better understood in terms of the relevance and trivialness of a necessary condition (Schneider and Wagemann, 2012: 325).

\section{Data and calibration}

For each group, our central unit of analysis, we calibrate scores on the outcome (ethnopolitical protest) and on each of the five explanatory conditions. In this context, calibration means that we transform the available 'raw' data into fuzzy-set membership scores. Before discussing the individual conditions, we must make a general remark about the time frame. Because our dataset covers the period from 1991 to 2003, we first need to calculate overall scores which typify a case on the outcome and the conditions for this 13-year period. In our analysis, we use the arithmetic mean because we aim to cover in a single indicator both the overall trend, as well as extreme values, but do not aim to prioritize either of these. The mean provides the best available measure to do so. Needless to say, in the interpretation of the results, the coding needs to be kept in mind, as using a single measure for a 13-year period allows us to capture overall differences in patterns of protest mobilization but not specific dynamics within groups over time. While variants of QCA were developed to address temporal dynamics (e.g. Caren and Panofsky, 2005), the configurational approach is generally seen as being stronger in analyzing relatively enduring patterns.

The outcome to be explained in this study is 'ethnopolitical protest'. Following the framework outlined above, there are five conditions employed in this analysis: two contextual factors (level of democracy and degree of ethnic fractionalization) and three group-related factors (territorial concentration, political discrimination, and national pride). In the remainder of this section, Appendix 1 Table 4 presents a detailed overview of the calibration of the raw data while Appendix 1 Table 5 presents both the raw scores and the calibrated fuzzy-set scores for the outcome and conditions for the 29 ethnic groups in the sample. Please refer to these tables in Appendix 1 for more details.

The outcome variable, ethnopolitical protest, is defined from the initial 'prot' indicator of the MAR data. ${ }^{2}$ The scores of protest range from 0 to 5, with higher scores coding more intense protest actions. The crossover score isolating weak and strong protest is placed at an average value of 1.5. This threshold is used because it indicates the overall transition from a silent form of protest, verbal opposition ( prot $=1)$, to a more dynamic form of protest, symbolic resistance ( $\operatorname{prot}=2$ ).

Territorial concentration is a condition originating from the 'groupcon' indicator in MAR, which measures the extent to which an ethnic group forms a compact regional community or, conversely, has an urban or country-wide dispersion. Those ethnic communities that are coded as widely dispersed (groupcon $=0$ ) and primarily urban minorities (groupcon $=1$ ) are considered territorially dispersed minorities. Correspondingly, ethnic communities that are the majority in one region (groupcon $=2$ ) or that are entirely concentrated in one region (groupcon $=3$ ) are coded as territorially concentrated minorities. To distinguish the distinction between the dispersed and concentrated communities, the crossover point of this condition is established at a value of 1.25.

Political discrimination derives from the 'poldis' indicator in MAR and captures discrimination practices toward minority groups that vary from no discrimination (poldis $=0$ ) to exclusive and 
repressive policies toward a minority group (poldis $=4$ ). The crossover point from absence to presence of discrimination is established at an average value of .75, which represents the edge separating values of 0 (no discrimination) and 1 (neglect/remedial policies).

Level of democracy (dem) originates from the 'fh ipolity2' indicator which is recorded by the Quality of Governance $(\mathrm{QoG})^{3}$ data. This measurement is a combined Freedom House and Imputed Polity annual democracy score calculated in terms of civil liberties and political rights at the country level. This democracy index ranks countries on a scale from 0 (strong autocracies) to 10 (strong democracies). Following the guidelines established by the Polity project (Jaggers and Gurr, 1995), the crossover point between non-democratic and democratic is established at a value of 7 (neither democratic nor transitional/autocratic).

Ethnic fractionalization derives from the 'ethfract' measure in QoG data. It records the probability that two randomly selected individuals in a country will belong to different ethnic groups (Fearon, 2003: 208). Ethnic fractionalization scores range from a perfectly homogenous society (0) to a highly fragmented country (1). The fuzzy-set crossover point is established at a middle value between 0 and 1 (.495).

National pride (pride) measures the average attachment among members of a minority group with their country of residence. It derives from the ' $\mathrm{g} 006$ ' indicator in the European Values Survey (EVS). ${ }^{4}$ The initial national pride scores range from 'not at all proud' $(0)$ to 'very proud' (3). The crossover point is established at an average value of 1.5 , which reflects the scores between 'not proud' (1) and 'quite proud' (2).

\section{Analysis}

In line with the accepted standards in fuzzy-set methodology (Ragin, 2009; Schneider and Wagemann, 2010), the analysis is performed in two steps: first, we analyze necessary conditions and then analyze sufficient conditions. This study takes into account the asymmetrical nature of the social phenomenon of ethnic protest by running separate analyses both for the presence of the outcome (strong protest) and the absence of the outcome (weak protest). ${ }^{5}$

\section{Necessary conditions}

The analysis of necessity includes the presence and absence of all conditions in relation to the presence and absence of the outcome. Table 1 presents the outcome of the necessity analysis. With a standard consistency threshold of .90 (Ragin, 2009: 118; cf. Schneider and Wagemann, 2012: 139143), we find one necessary condition for the presence of strong ethnic protest and a different condition for its absence. Two preliminary remarks before we discuss the results are as follows: First, while it may be intuitively plausible that a necessary condition for weak protest is not the negation of the necessary condition for strong protest, such causal asymmetry is rarely observed in the literature on ethnic mobilization. Hence, we stress the importance of conducting a separate analysis for the status of necessity for strong and weak protest. Second, because the subset relation is not perfectly consistent in either of the two conditions, these conditions should be considered as 'quasi-necessary conditions'. For both conditions, the modest coverage scores also indicate that they are likely insufficient for understanding the full variation in the outcomes of strong and weak protest.

First, our evidence suggests that strong territorial concentration is a quasi-necessary condition for the occurrence of strong protest. While this observation seems to corroborate Toft's (1996, 2003) argument about the importance of territorial concentration for ethnic contention, our analysis allows us to make a more precise statement about the set-theoretic nature of the relation, namely, 
Table I. Analysis of necessary conditions for strong and weak protest.

\begin{tabular}{|c|c|c|c|c|}
\hline & \multicolumn{2}{|c|}{ Strong protest } & \multicolumn{2}{|l|}{ Weak protest } \\
\hline & Consistency & Coverage & Consistency & Coverage \\
\hline DEM & 0.74 & 0.71 & 0.62 & 0.58 \\
\hline dem & 0.56 & 0.60 & 0.69 & 0.72 \\
\hline ETHFRACT & 0.68 & 0.76 & 0.57 & 0.62 \\
\hline ethfract & 0.66 & 0.61 & 0.77 & 0.70 \\
\hline GROUPCON & $0.90 *$ & 0.62 & 0.78 & 0.53 \\
\hline groupcon & 0.32 & 0.60 & 0.44 & 0.82 \\
\hline POLDIS & 0.52 & 0.74 & 0.33 & 0.47 \\
\hline poldis & 0.63 & 0.49 & 0.82 & 0.62 \\
\hline PRIDE & 0.71 & 0.54 & $0.93 *$ & 0.69 \\
\hline pride & 0.60 & 0.90 & 0.38 & 0.56 \\
\hline
\end{tabular}

Source: Minorities at Risk (MAR), European Value Survey (EVS), Quality of Governance (QoG).

Note: Uppercase letters refer to the presence of a condition, and lowercase letters to the absence of a condition.

*consistency score $\geq .90$.

rather than 'inducing' ethnic contention, our analysis suggests that territorial concentration is a necessary rather than sufficient condition. In other words, without having a high degree of territorial concentration, ethnic groups lack the organizational capacity to mobilize, but being strongly concentrated within a specific territory does not alone suffice to explain why some groups mobilize toward strong protest while others do not. We come back to this factor below when discussing sufficient conditions.

Second, for weak protest, we find that the presence of strong feelings of national pride among members of a minority group is a quasi-necessary condition for weak protest. Again, while this finding coincides with the constructivist argument that an overarching sense of belonging is important for the interethnic cohesion of multi-ethnic societies (Modood, 2005), our analysis allows us to make a more precise statement about the set-theoretic relation between pride and protest. In other words, members of ethnic groups that display weak protest nearly always share an overly strong feeling of national pride, but this condition does not imply that groups with a strong feeling of national pride are, by definition, always weakly mobilized.

\section{Sufficient conditions for strong protest}

In fsQCA, the analysis of sufficiency is performed on the basis of a truth table, which reduces causal complexity by outlining the logical combinations of all conditions and linking these combinations to the presence or the absence of the outcome. In our analysis, the truth table is based on five conditions and includes $32\left(2^{5}\right)$ truth table rows or vector space corners. ${ }^{6}$ Of these 32 logical combinations, 17 are represented by the 29 minority groups in our dataset. The truth table analysis then proceeds in two steps. First, for each of these 17 combinations, we evaluate the 'consistency' of the evidence with respect to the argument that the cases with this combination of conditions constitute a subset of the cases with the given outcome (the consistency scores are reported in Appendix 1 Tables 6 and 7). ${ }^{7}$ Second, we 'minimize' the truth table on the basis of the QuineMcCluskey algorithm, excluding those rows with a consistency score of less than $.80 .^{8}$

Table 2 shows the parsimonious solution, which consists of four causal configurations that can be seen as sufficient conditions for strong ethnic protest. ${ }^{9}$ The table includes the 13 minority groups 
Table 2. Fuzzy-set analysis of sufficient conditions for strong protest (parsimonious solution).

\begin{tabular}{|c|c|c|c|c|c|}
\hline & & Config & ration (with set & embership $>0.5$ & \\
\hline & & 1 & 2 & 3 & 4 \\
\hline Cases & $\begin{array}{l}\text { Membership in } \\
\text { outcome }\end{array}$ & Pride & $\begin{array}{l}\text { GROUPCON } \\
* \text { DEM }\end{array}$ & $\begin{array}{l}\text { GROUPCON } \\
\text { * POLDIS }\end{array}$ & $\begin{array}{l}\text { GROUPCON } \\
* \text { POLDIS }\end{array}$ \\
\hline & & & * ETHFRAC & * ETHFRAC & DEM \\
\hline Albanians FYROM & 0.85 & 0.75 & 0.56 & 0.58 & 0.56 \\
\hline Basques Spain & 0.93 & 0.62 & 0.51 & & \\
\hline Catalans Spain & 0.56 & & 0.51 & & \\
\hline Catholics N. Ireland & 0.89 & & & & 0.58 \\
\hline Crimean Russians Ukraine & 0.89 & 0.94 & & & \\
\hline Gagauz Moldova & 0.73 & & & 0.54 & \\
\hline Hungarians Romania & 0.59 & & & & 0.7 \\
\hline Hungarians Yugoslavia & 0.85 & 0.57 & & 0.95 & \\
\hline Kosovo Albanians & 0.98 & 0.59 & & 0.92 & \\
\hline Russians Estonia & 0.79 & & 0.54 & 0.54 & 0.78 \\
\hline Russians Latvia & 0.85 & 0.71 & & & \\
\hline Russians Ukraine & 0.52 & 0.66 & & & \\
\hline Serbs FYROM & 0.57 & & 0.56 & & \\
\hline Consistency & & 0.90 & 0.93 & 0.87 & 0.91 \\
\hline Coverage (raw) & & 0.60 & 0.48 & 0.37 & 0.34 \\
\hline Consistency cutoff: & 0.82 & & & & \\
\hline Solution coverage: & 0.81 & & & & \\
\hline Solution consistency: & 0.88 & & & & \\
\hline
\end{tabular}

Source: Truth table presented in Appendix I Table 6.

Note: Uppercase letters refer to the presence of a condition, and lowercase letters to the absence of a condition.

that are covered by this solution. For each case, we indicate the degree of membership in the outcome (the set of strong protest) and the case's membership in one or more of the causal configurations (if membership is higher than .5). Cases can have membership in more than one configuration or in all configurations, as is the case of the Albanians in Macedonia, because these sets may overlap. The overall solution consistency is high (.88), and the coverage is good (.81).

The first substantive observation is that there is only one condition, namely a weak sense of national pride, which is individually sufficient for strong protest (configuration 1). This suggests that feelings of national pride for ethnic groups, such as Albanians in Macedonia and Kosovo, Russians in Ukraine and Latvia, or Basques in Spain, are sufficiently weakened on institutional or primordial grounds to incite strong, yet peaceful, protest. While this coincides with constructivist literature that strongly emphasizes the importance of feelings of national identity in modeling the intensity of ethnic contention (Guibernau, 2006; Korostelina, 2004; Smith, 1991), our caseoriented analysis allows for a geographical specification of this argument. In particular, we observe that most cases covered by this solution are based in states that emerged after the collapse of the Soviet Union and communist Yugoslavia. In that context, after the former states collapsed, some ethnic groups that once held dominant positions (e.g. Russians in Ukraine and Latvia within the Soviet Union, Albanians and Hungarians in Kosovo and Vojvodina autonomies within socialist Yugoslavia) shifted their condition to a minority-at-risk status. By default, the newly emerged states have national identity projects that mainly attract the current ethnic majority groups. At the 
same time, the limited time that elapsed because the emergence of new states (and new minority statuses) did not allow for the construction of a strong sense of national pride among minority groups, which could enhance interethnic cohesion while reducing conflict.

Second, we observe that the other four conditions included in the analysis are all the so-called INUS conditions, that is, conditions that are themselves insufficient but nonetheless necessary parts of an unnecessary but sufficient combination of conditions. The analysis of sufficiency thus confirms that territorial concentration is not individually sufficient to understand strong ethnic protest. This, of course, does not imply that this factor is not relevant. By contrast, the territorial factor, as a quasi-necessary condition, is a key predictor for ethnic mobilization, as we would expect from a primordialist (Gurr, 2000; Toft, 1996, 2003) or a mobilization perspective (Weidmann, 2009). In terms of our theoretical framework, capacity matters but not without identity and/or opportunity. While such interactions can also be modeled in statistical analyses, we are not aware of any studies in which territorial concentration is explicitly modeled in interaction with contextual factors such as level of democracy or ethnic fractionalization or, at the group level, with a factor such as political discrimination in explaining protest mobilization. As a result, our findings challenge the standard assumption of the existence of an independent effect of a minority group's territorial concentration.

The next INUS condition we would like to highlight is political discrimination. While the evidence on the direction of the relation between political discrimination and protest is in line with the established assumptions (i.e. discrimination results in strong protest), we find that discrimination is not an individually sufficient condition. This finding is illustrated by groups such as the Basques and Catalans in Spain, which continuously negotiated their demands through protest but in the absence of a strong practice of political inequality enacted against them. In addition, we also find groups, such as Greeks in Albania or the Roma in Bulgaria, which do face strong political discrimination, yet do not manage to mobilize beyond weak manifestations of discontent.

Finally, we point to the two contextual factors, level of democracy and ethnic fractionalization, which are also INUS conditions for strong protest. Given the ambiguity in the literature surrounding the role of democracy in managing ethnic contention, we found that a consolidated democratic context is relevant, yet neither a necessary nor sufficient condition for strong protest. In other words, consolidated democracies may provide the opportunity for strong peaceful protest that groups may not otherwise have in lesser democratic contexts (Guerin et al., 2004; Scarritt et al., 2001). Yet, precisely by managing to address ethnic diversity peacefully, strong democracies also decrease the desire of ethnic groups for continuing ethnic dissent (Benson and Saxton, 2010; Saideman and Ayres, 2000). A consolidated democratic environment and high ethnic fractionalization are each relevant in two of the four causal configurations and, when configured together with territorial concentration (e.g. Basques and Catalans in Spain), they explain strong protest (see Gurr, 1993b). Only when the condition of weak national pride is present do either of these two contextual factors matter.

\section{Sufficient conditions for weak protest}

The analysis of sufficient conditions for weak protest uses the same five causal conditions employed for the analysis of strong protest. Appendix 1 Table 7 presents the truth table that reveals the settheoretic consistency of causal combinations as subsets of weak protest. With a consistency cutoff of $.85,{ }^{10}$ there are eight configurations where the evidence from the empirical cases indicates a sufficiency subset relation. The parsimonious solution is presented in Table 3 .

The fuzzy-set analysis, on the basis of the available cases, indicates that there are four conjuncturally sufficient combinations linked to weak ethnic protest. The first aspect to be observed is the 
Table 3. Fuzzy-set analysis of sufficient conditions for weak protest (parsimonious solution).

\begin{tabular}{|c|c|c|c|c|c|}
\hline & & \multicolumn{4}{|c|}{ Configuration (with set membership $>0.5$ ) } \\
\hline & & 5 & 6 & 7 & 8 \\
\hline \multirow[t]{3}{*}{ Cases } & Membership & PRIDE & PRIDE & PRIDE & PRIDE \\
\hline & in outcome & $*$ poldis & $*$ poldis & $*$ dem & *groupcon \\
\hline & & * ethfrac & $*$ dem & * ethfrac & \\
\hline Croats Bosnia & 0.73 & & 0.66 & & \\
\hline Greeks Albania & 0.53 & & & 0.59 & \\
\hline Lezgins Azerbaijan & 0.3 & 0.86 & 0.88 & 0.86 & 0.65 \\
\hline Muslims Bosnia & 0.85 & & 0.87 & & \\
\hline Poles Belarus & 0.97 & 0.63 & 0.63 & 0.68 & \\
\hline Roma Bulgaria & 0.64 & & & & 0.83 \\
\hline Roma FYROM & 0.91 & & & & 0.65 \\
\hline Russians Azerbaijan & 0.97 & 0.76 & 0.76 & 0.86 & 0.65 \\
\hline Russians Belarus & 0.97 & 0.6 & 0.6 & 0.6 & 0.6 \\
\hline Russians Georgia & 0.67 & 0.61 & 0.65 & 0.51 & 0.65 \\
\hline Sardinians Italy & 0.98 & 0.86 & & & \\
\hline Scots UK & 0.64 & 0.74 & & & \\
\hline Serbs Bosnia & 0.56 & & 0.87 & & \\
\hline Slavs Moldova & 0.44 & & 0.51 & & 0.51 \\
\hline South Tyrolians & 0.64 & 0.75 & & & \\
\hline Turks Bulgaria & 0.53 & 0.7 & & & \\
\hline Consistency & & 0.83 & 0.87 & 0.88 & 0.89 \\
\hline Coverage (raw) & & 0.64 & 0.56 & 0.50 & 0.44 \\
\hline Consistency cutoff: & 0.85 & & & & \\
\hline Solution coverage: & 0.89 & & & & \\
\hline Solution consistency: & 0.82 & & & & \\
\hline
\end{tabular}

Source: Truth table presented in Appendix Table 7.

Note: Uppercase letters refer to the presence of a condition, and lowercase letters to the absence of a condition.

importance of the necessary condition of strong national pride. This condition is present in all four configurations, which means that all ethnic groups with a weak protest score are also characterized by a strong sense of national pride. The causal relevance of this condition underscores the significance of the symbolic construction of communities and the cohesive force of national identity even in the face of ethnic diversity. This finding confirms previous studies linking national pride with softer ethno-social tensions (Evans and Kelley, 2002; Tilley and Heath, 2007).

The analysis clearly demonstrates that strong national pride, however, is not individually sufficient for weak protest; only in conjunction with one or more of the other causal conditions does strong national pride explain weak protest. Empirically, the fact that strong pride is not individually sufficient for weak protest is illustrated by the two 'contradictory' cases included in this part of the analysis, namely the Lezgins in Azerbaijan and the Slavs in Moldova. In these two instances, despite a strong sense of national pride among the minority group members, we find a strongly mobilized form of ethnic protest. In the case of the Lezgins, in particular, their strong protest mobilization in the analyzed time-period is puzzling, given that they display strong membership in all four of the causal configurations outlined in Table 3, which would be expected to be linked to weak protest rather than the opposite. After all, apart from being largely assimilated among the majority Azeri population, they are neither strongly territorially concentrated nor politically discriminated 
against, and moreover, they find themselves in an authoritarian context where political protest is quickly perceived as challenging state authority. While Ware and Kisriev (2009) suggest that the Lezgin mobilization signals a strong form of civic engagement rather than protest expressing political dissatisfaction, this case would clearly qualify for further process-tracing analysis if scholars were to look for a 'deviant' case.

Moldova is deviant to a lesser extent due to extremely ambiguous membership (0.51) in both causal configurations and also a very moderate membership in the set of strong protest $(0.56)$. In this ambiguous case, the ethnopolitical mobilization of Slavs (mainly Russians and Ukrainians) is influenced by the dynamics of the frozen conflict in the separatist Transnistrian region. Despite the efforts of Moldovan authorities to not antagonize the Slavic population, interethnic tensions are still regularly exhibited among the Moldovan and Slavs in the country. In this context, the moderately strong sense of national pride among the Slavic population in Moldova appears to be outweighed by the latent ethnic conflict in the country. This case-oriented configurational analysis thus highlights that it would be controversial to consider the Slavs in Moldova as a 'typical case' for either weak or strong protest. In other words, it should not be used in a subsequent processtracing analysis to further explore the causal mechanisms that link the causal configurations outlined in Table 3 to the outcome.

Subsequently, we find weak ethnic protest among groups with strong national pride and dispersed territorial location. Many Roma minorities, for example, in Bulgaria and Macedonia, simply lack political cohesion for strong mobilization because of wide group dispersion. Other dispersed, mainly urban minorities such as Russians in Azerbaijan, Belarus, and Georgia find themselves targets for more aggressive nation-state integration policies such as proficiency in the host-state language, national military service, and citizenship regulation policies. These measures weaken the ethnic belonging of the minority group while enforcing national attachment and civic participation. Hence, in such cases, it may be unclear whether weak protest is to be understood by either the lack of an incentive (in terms of a relatively strong affiliation with the majority population) or the lack of an opportunity to mobilize (in terms of the territorial dispersion).

All other cases of weak protest target those groups with strong national pride and at least two out of the following three conditions: lack of political discrimination, weak ethnic fractionalization, and the absence of a consolidated democracy. All cases covered by weak democratic values (configurations 6 and 7) come from Central and Eastern Europe, a region struggling with the democratic transition during the 1990s and the early 2000s. When combined with a low degree of ethnic fractionalization in the country, minorities find it difficult to mobilize in a transitional environment where national identity projects take precedence over the accommodation of minority interests (Rabushka and Shepsle, 1972).

Finally, the configuration (5) with the largest empirical coverage includes not only cases in nondemocratic contexts but also the 'weaker' (salient?) ethnic minorities in democratic Western Europe, such as Sardinians, South Tyrolians, and the Scottish. At the group level, we find that in all these cases, the relative strong sense of national pride among the minority relates to a lack of political discrimination of that group by the majority population, and thus, arguably, reflects at least partly a successful assimilation project. At the contextual level, we find that the relatively low degree of ethnic fractionalization, as in Italy and the United Kingdom, also matters for understanding the weakness of ethnic protest.

\section{Implications and conclusion}

This study attempts to answer a fundamental question: under what conditions do ethnic groups intensify or moderate their protest behavior? Most of the existing research focuses on violent forms 
of ethnic contention; hence, there is a disproportionately low amount of evidence explaining the ladder of protest mobilization. This study develops a new, integrated model of assessing protest mobilization, viewed from the set-theoretic lenses of necessary and sufficient conditions.

The configurational analysis uses an adapted model of ethnopolitical behavior developed by Gurr (1993b), which includes five contextual and group conditions with a proven empirical record for understanding what drives ethnic groups to mobilize. In our model, strong and weak protest are choices of differing intensity, and their selection is an outcome of configurations between opportunity (level of democracy, ethnic fractionalization), capacity (territorial concentration), incentive (political discrimination), and identity (national pride) conditions for a sample of 29 ethnic communities in Europe. In traditional quantitative models, these conditions are over-generalized across all groups and analyzed in a causally atomic manner. By contrast, we employ a QCA technique fuzzy-set analysis - which is specifically geared toward matching groups of cases to specific analytical configurations of causal conditions.

There are two main advantages of using QCA rather than statistical methods in our study. First, QCA targets protest mobilization from a different empirical angle than quantitative analysis. Precisely, QCA aims to observe the configurational logic of five contextual and group conditions leading to both strong and weak protest. Comparatively, statistical methods isolate the effects of a specific factor, while controlling for all possible confounders, to observe the individual impact of that factor on the dependent variable. In the realm of the complexity of characterizing protest mobilization, isolating the effects of all independent indicators would be problematic because one cannot always control for all confounders. Thus, the use of a configurational logic provides a more complex and complete explanation to the observed outcome. Second, statistical methods focus on variables and less on cases. QCA, on the other hand, uses a case-study approach to conduct the analysis, thus linking theory, cases, and results.

In summary, the analysis is novel in several ways. First, the fuzzy-set analysis lends credence to a configurational view on ethnic protest, in which individual causal conditions have a different settheoretic status and often need to be understood in a conjunctural manner. The results show that contextual factors of level of democracy and ethnic fractionalization and the group-level condition of political discrimination, indeed matter, but they are neither necessary nor individually sufficient conditions for ethnic protest. We reveal thus the ambiguous side of assuming the impact of "independence" on each factor with respect to ethnic contention. In other words, while a number of the so-called INUS conditions are relevant elements in the causal configuration in which interethnic relations are shaped, our analysis contrasts with the literature which predominantly outlines causal conditions as independently sufficient explanations of either strong or weak protest. By contrast, the two remaining group-level factors - territorial concentration and national pride - stand out in our analysis as having direct individual relevance in explaining outcomes of protest. In particular, territorial concentration is a necessary condition for strong protest, while a strong feeling of national pride is a necessary condition for weak protest. Furthermore, we also find that the absence of national pride is an individual, sufficient condition for strong ethnic protest.

Second, this study points to causal 'asymmetry', representing complex phenomena such as ethnic contention. Causal asymmetry is often overlooked in the literature, mainly because it cannot be captured easily with the standard data modeling techniques. Our findings demonstrate that what explains weak protest is not automatically the negation of the conditions (or configuration of conditions) that explains strong protest. For example, territorial concentration is a quasi-necessary condition for strong protest, while a strong sense of national pride fulfills the status of necessity for weak protest. The implication of this finding for the semantics of conflict is noteworthy: while understanding the configuration of contention is important, looking into the dynamics of noncontention reveals not a mirror image, but a different picture. 
Third, the strength of our configurational analysis is that we are able to understand different causal configurations which are driving ethnic protest among most of the groups in our study, and it can highlight those cases that are analytically similar while identifying and discussing the 'outliers' that do not fit well with our models. While traditional quantitative methods also include ways of highlighting empirical outliers, this is typically not a feature which is emphasized much. QCA, by contrast, through its case-oriented nature explicitly matches causal configurations with empirical cases and thus provides a useful starting point for further process-tracing analysis of typical and deviant cases (Schneider and Rohlfing, 2013).

This study can be considered a starting point for further research in a number of ways. Our models can be replicated and conducted in different regional contexts. Choosing different outcomes, ethnic violence for example, would provide additional configurational evidence to complement the obtained results. Additionally, other relevant conditions can be identified and included in the model. Important comparative evidence can emerge if minorities 'at risk' and 'not at risk' or minority and majority groups were compared in the light of their mobilization patterns. Finally, a time dimension could be included to test whether the configurational structure of ethnic contention holds dynamic evidence.

\section{Funding}

This research received financial support from the Marie Curie COFUND scheme and the National Research Fund of Luxembourg.

\section{Notes}

1. For example, a number of minorities from Greece, France, Lithuania, Slovakia, Ukraine, Georgia, and Romania were excluded from the initial sample because no group-level data on national pride were available in EVS.

2. The MAR data are computed from various sources, including human rights reports, governmental and expert opinion, journalistic accounts, reports from the international organizations, and so on. Careful attention is given to the data to control for the coding bias and to minimize the subjective inclusion of the information coming from the use of many qualitative sources. The guideline of the MAR sampling procedure can be found on the project website: http://www.cidcm.umd.edu/mar/.

3. The QoG data are coded by researchers at the Quality of Government Institute, Goteborg University. This dataset is a compilation of different types of smaller datasets and was built on the basis of expert coded indicators, aggregated individual-level survey data, international organizations' expert data, or different demographic, social and political measures. For more information regarding this dataset, see Teorell et al. (2009).

4. EVS is a cross-national dataset with individual-level survey data gathered among European countries. It provides evidence on the attitudes, beliefs, preferences, values, and opinions of European people in multicultural countries. This study uses information gathered in two extensive data-collection waves: 1993-1999 and 2000-2004.

5. We use the software fs/QCA 2.0 for our analyses.

6. Because cases in fuzzy-set analysis have membership in the presence of a condition and its negation, rows of fuzzy-set truth tables are properly understood as corners of a multidimensional vector space (Ragin, 2009: 104).

7. For reasons of space, Appendix 1 Tables 6 and 7 only show the logical combinations that are covered by empirical cases, hence excluding the so-called logical remainders - that is, combinations of conditions that are not covered by empirical cases.

8. A consistency score of .80 or higher is generally seen as the minimum cutoff point for a reliable analysis of sufficiency; however, researchers are also encouraged to explore the truth table for logical contradictions (Ragin, 2009: 121; Schneider and Wagemann, 2012: 127). See also note 10. 
9. For reasons of limited space, we present only the 'parsimonious solution' and not the 'complex' and 'intermediate' solutions (available upon request from the authors). The parsimonious solution excludes all logically redundant conditions and is the superset of the intermediate and complex solutions (Ragin, 2009: 118). In this case, the parsimonious solution consists of four alternative, equally fitting solutions with two so-called essential prime implicants: pride (1) and GROUPCON * POLDIS * DEM (4). There are three logical alternatives for prime implicants 2 and 3 presented in Table 2: (DEM*ETHFRAC*GROUPCON + dem*ETHFRAC*POLDIS $), \quad($ dem*ETHFRAC*POLDIS + DEM*ETHFRAC*poldis), and $\left(\right.$ DEM $^{*}$ ETHFRAC* ${ }^{*}$ poldis + ETHFRAC *GROUPCON*POLDIS). These alternatives are not more, or less, 'true', but in this case, it would be logically redundant to include more than two of these so-called inessential prime implicants. However, for a completely fitting solution, at least two prime implicants need to be included (on logically redundant prime implicants; see, Schneider and Wagemann, 2012: 108111). We select the inessential prime implicants on the basis of our theoretical expectations (on essential or inessential prime implicants, see also Thiem and Dusa, 2012: 74).

10. We apply a higher consistency threshold for the sufficiency analysis of weak ethnic protest to avoid the inclusion of the truth table rows represented by the Catalans in Spain, the Serbs in FYROM, the Russians in Ukraine, and the Crimean Russians in Ukraine in the sufficiency analysis of the presence and absence of ethnic protest (see Appendix 1 Tables 5 and 6). Including these groups in both analyses could lead to a situation where the same configuration can be quasi-sufficient for an outcome and its negation, which should be avoided (Cooper and Glaesser, 2011). Because we consider all four cases as instances of strong protest (fuzzy-set score of protest $>.5$ ), we argue that these cases are better included in the analysis of the presence rather than absence of strong protest. This methodology is in line with the standards that advise against applying a consistency threshold mechanically (Ragin, 2009: 118).

\section{References}

Alesina A, Devleeschauwer A, Easterly W, et al. (2003) Fractionalization. Journal of Economic Growth 8: $155-194$.

Almond GA and Verba S (1989 [1963]) The Civic Culture, Political Attitudes and Democracy in Five Nations Newbury Park. London: SAGE.

Barnes S, Kaase M, and Allerbeck KR (eds.) (1979) Political Action: Mass Participation in Five Western Societies. Beverly Hills, CA: SAGE.

Benson M and Rochon T (2004) Interpersonal trust and the magnitude of protest: A micro- and macro-level approach Comparative Political Studies 20: 1-23.

Benson M and Saxton G (2010) The dynamics of ethnonationalist contention. British Journal of Political Science 40(2): 305-331.

Berelson BR, Lazarsfeld PF and McPhee WN (1954) Voting: A Study of Opinion Formation in a Presidential Campaign. Chicago, IL: University of Chicago Press.

Braumoeller BF and Goertz G (2000) The methodology of necessary conditions. American Journal of Political Science 44(4): 844-858.

Caren N and Panofsky A (2005) TQCA: A technique for adding temporality to qualitative comparative analysis. Sociological Methods \& Research 34(2): 147-172.

Catterberg G (2003) Evaluations, referents of support, and political action in new democracies. International Journal of Comparative Sociology 44(3): 173-198.

Cederman L-E and Girardin L (2005) Beyond fractionalization: Mapping ethnicity onto nationalist insurgencies. Paper presented at the Dissagregating the Study of Civil War and Transnational Violence conference, University of California Institute of Global Conflict and Cooperation, San Diego, CA, 7-8 March.

Cederman L-E, Weidmann NB and Gleditsch KS (2011) Horizontal inequalities and ethno-nationalist civil war: A global comparison. American Political Science Review 105(3): 457-477.

Cederman L-E, Wimmer A and Min B (2010) Why do ethnic groups rebel? New data and analysis. World Politics 62(1): 87-119.

Cooper B and Glaesser J (2011) Paradoxes and pitfalls in using fuzzy set QCA: Illustrations from a critical review of a study of educational inequality. Sociological Research Online 16(3): 8. 
Cunningham DE (2011) Barriers to Peace in Civil Wars. Cambridge, New York: Cambridge University Press.

Davenport C (1995) Multi-dimensional threat perception and state repression: An inquiry into why states apply negative sanctions. American Journal of Political Science 39(3): 683-713.

Davenport C (1999) Human rights and the democratic proposition. Journal of Conflict Resolution 43(1): 92-116.

DeNardo J (1985) Power in Numbers: The Political Strategy of Protest and Rebellion. Princeton, NJ: Princeton University Press.

Dogan M (1994) The decline of nationalisms within Western Europe. Comparative Politics 29(3): 281-305.

Evans MDR and Kelley J (2002) National pride in the developed world: Survey data from 24 nations. International Journal of Public Opinion Research 14(3): 303-338.

Fearon J and Laitin D (2003) Ethnicity, insurgency, and civil war. American Political Science Review 97(1): $75-90$.

Fearon JD (2003) Ethnic and cultural diversity by country. Journal of Economic Growth 8: 195-222.

Fox J (2003) Trends in low intensity ethnic conflict in democratic states in the post-Cold War era: A large N study. Review of International Affairs 2(3): 54-70.

Gaertner SL, Dovidio JF, Nier JA, et al. (1999) Across cultural divides: The value of a superordinate identity. In: Prentice D and Miller D (eds) Cultural Divides: Understanding and Overcoming Group Conflict. New York: SAGE, pp. 173-212.

Gherghina S and Jiglau G (2011) Explaining ethnic mobilisation in post-communist countries. Europe-Asia Studies 63(1): 49-76.

Gleditsch KS and Ruggeri A (2010) Political opportunity structures, democracy, and civil war. Journal of Peace Research 47(3): 299-310.

Grosby S (1994) The verdict of history: The inexpungeable tie of primordiality - A response to Eller and Coughlan. Ethnic and Racial Studies 17(1): 164-171.

Guerin D, Petry F and Crete J (2004) Tolerance, protest and democratic transition: Survey evidence from 13 post-communist countries. European Journal of Political Research 43: 371-395.

Guibernau M (2006) National identity, devolution and secession in Canada, Britain and Spain. Nations and Nationalism 12(1): 51-76.

Gurr TR (1989) Violence in America: Protest, Rebellion, Reform. Newbury Park, CA: SAGE.

Gurr TR (1993a) Minorities at Risk: A Global View of Ethnopolitical Conflicts. Washington, DC: United States Institute of Peace Press.

Gurr TR (1993b) Why minorities rebel: A global analysis of communal mobilization and conflict since 1945. International Political Science Review 14(2): 161-201.

Gurr TR (1994) Peoples against states: Ethnopolitical conflict and the changing world system. International Studies Quarterly 38(3): 347-377.

Gurr TR (1996) Minorities, nationalism and ethnopolitical conflict. In: Crocker CA and Hampson FO (eds) Managing Global Chaos: Sources of and Responses to International Conflict. Washington, DC: United States Institute of Peace Press, pp. 53-79.

Gurr TR (2000) Peoples versus States: Minorities at Risk in the New Century. Washington, DC: United States Institute of Peace Press.

Gurr TR and Moore WH (1997) Ethnopolitical rebellion: A cross-sectional analysis of the 1980s with risk assessments for the 1990s. American Journal of Political Science 41(4): 1079-1103.

Heymann PB (1992) Towards Peaceful Protest in South Africa. Pretoria, South Africa: HSRC Publishers.

Horowitz D (1993) Democracy in divided societies. Journal of Democracy 4(4): 18-38.

Horowitz D (2000) Ethnic Groups in Conflict. Berkeley, CA: University of California Press.

Horowitz D (2004) The primordialists. In: Conversi D (ed.) Ethnonationalism in the Contemporary World: Walker Connor and the Study of Nationalism. London; New York: Routledge, pp. 72-82.

Huddy L and Khatib N (2007) American patriotism, national identity, and political involvement. American Journal of Political Science 51(1): 63-77.

Huntington S (1996) The Clash of Civilizations and the Remaking of World Order. New York: Simon \& Schuster. 
Inglehart R (1990) Culture Shift in Advanced Industrial Society. Princeton, NJ: Princeton University Press.

Inglehart R and Catterberg G (2002) Trends in political action: The developmental trend and the posthoneymoon decline. International Journal of Comparative Sociology 43(3-5): 300-316.

Jaggers K and Gurr TR (1995) Tracking democracy's third wave with the Polity III data. Journal of Peace Research 32(4): 469-482.

Kaase M (2010) Democracy and political action. International Political Science Review 31(5): 539-551.

Koopmans R (1993) The dynamics of protest waves: Western Germany, 1965-1989. American Sociological Review 58(5): 637-658.

Korostelina K (2004) The impact of national identity on conflict behavior: Comparative analysis of two ethnic minorities in Crimea. International Journal of Comparative Sociology 45(3-4): 213-230.

McAdam D, Tarrow S and Tilly C (1996) To map contentious politics. Mobilization: An International Quarterly 1(1): 17-34.

McKay J (1982) An exploratory synthesis of primordial and mobilizationist approaches to ethnic phenomena. Ethnic and Racial Studies 5(4): 395-420.

Mackie JL (1980) The Cement of the Universe: A Study of Causation. Oxford: Oxford University Press.

Mansbach R and Rhodes E (2007) The national state and identity politics: State institutionalisation and 'Markets' of national identity. Geopolitics 12(3): 426-458.

Marsh A (1990) Political Action in Europe and the USA. London: Macmillan Publishers.

Marshall MG and Gurr TR (2003) Peace and Conflict, 2003: A Global Survey of Armed Conflicts, SelfDetermination Movements, and Democracy. Baltimore, MD: Center for International Development and Conflict Management, University of Maryland.

Martin B (1994) Protest in a liberal democracy. Philosophy and Social Action 20(1-2): 13-24.

Marx A, Rihoux B and Ragin C (2013) The origins, development, and application of Qualitative Comparative Analysis: The first 25 years. European Political Science Review. Epub ahead of print 22 February.DOI: $10.1017 / \mathrm{S} 1755773912000318$.

Minorities at Risk Project (MAR) (2005) Minorities at Risk Dataset. College Park, MD: Center for International Development and Conflict Management. Available at: http://www.cidcm.umd.edu/mar/ (accessed 18 May 2008).

Modood T (2005) Remaking Multiculturalism after 7/7. OpenDemocracy Ltd. Available at: http://www.openDemocracy.net (29 September 2005; accessed 20 September 2008).

Muller EN (1979) Aggressive Political Participation. Princeton, NJ: Princeton University Press.

Olzak S (1998) Ethnic protest in core and periphery states. Ethnic and Racial Studies 21(2): 187-217.

Olzak S and Tsutsui K (1998) Status in the world system and ethnic mobilization. Journal of Conflict Resolution 42(6): 691-720.

Posen BR (1993) The security dilemma and ethnic conflict. In: Brown ME (ed.) Ethnic Conflict and International Security. Princeton, NJ: Princeton University Press, 288 pp.

Rabushka A and Shepsle KA (1972) Politics in Plural Societies: A Theory of Democratic Instability. Columbus, $\mathrm{OH}$ : Merrill Publishers.

Ragin CC (1987) The Comparative Method: Moving Beyond Qualitative and Quantitative Strategies. Berkeley, Los Angeles and London: University of California Press.

Ragin CC (1989) The Comparative Method: Moving Beyond Qualitative and Quantitative Strategies. Berkeley, CA; Los Angeles, CA; London: University of California Press.

Ragin CC (2000) Fuzzy-Set Social Science. Chicago, IL: University of Chicago Press.

Ragin CC (2006) Set relations in social research: Evaluating their consistency and coverage. Political Analysis 14(3): 291-310.

Ragin CC (2008) Redesigning Social Inquiry: Fuzzy Sets and Beyond. Chicago, IL: University of Chicago Press.

Ragin CC (2009) Qualitative Comparative Analysis using Fuzzy Sets (fsQCA). In: Rihoux B and Ragin CC (eds) Configurational Comparative Methods: Qualitative Comparative Analysis (QCA) and Related Techniques. Thousand Oaks, CA; London: SAGE, pp. 87-121.

Rihoux B (2006) Qualitative Comparative Analysis (QCA) and related systematic comparative methods: Recent advances and remaining challenges for social science research. International Sociology 21(5): 679-706. 
Rihoux B and Ragin CC (2009) Configurational Comparative Methods: Qualitative Comparative Analysis (QCA) and Related Techniques. Thousand Oaks, CA; London: SAGE.

Saideman SM and Ayres RW (2000) Determining the causes of irredentism: Logit analysis of minority at risk data from the 1980s and 1990s. Journal of Politics 62(4): 1126-1144.

Saideman SM, Lanoue DJ, Campenni M, et al. (2002) Democratization, political institutions, and ethnic conflict: A pooled time-series analysis, 1985-1998. Comparative Political Studies 35(1): 103-129.

Sandovici ME and Listhaug O (2010) Ethnic and linguistic minorities and political participation in Europe. International Journal of Comparative Sociology 51(1-2): 111-136.

Saxton G and Benson M (2006) Structure, politics, and action: An integrated model of nationalist protest and rebellion. Nationalism and Ethnic Politics 12(2): 137-175.

Scarritt JR, McMillan SM and Mozaffar S (2001) The interaction between democracy and ethnopolitical protest and rebellion in Africa. Comparative Political Studies 34(7): 800-827.

Schneider CQ and Rohlfing I (2013) Combining QCA and process tracing in set-theoretic multimethod research. Sociological Methods Research. Epub ahead of print 22 March. DOI: $10.1177 / 0049124113481341$.

Schneider CQ and Wagemann C (2010) Standards of good practice in Qualitative Comparative Analysis (QCA) and fuzzy-sets. Comparative Sociology 9(3): 397-418.

Schneider CQ and Wagemann C (2012) Set-Theoretic Methods for the Social Sciences: A Guide to Qualitative Comparative Analysis. Cambridge: Cambridge University Press.

Smith AD (1986) The Ethnic Origin of Nations. Oxford: Basil Blackwell.

Smith AD (1991) National Identity. Reno, NV: University of Nevada Press.

Smith TW and Jarkko L (1998) National Pride: A Cross National Analysis. Chicago, IL: National Opinion Research Center, University of Chicago.

Snyder J (1999) When Voting Leads to Violence: Democratization and Nationalist Conflict. New York: Norton Books.

Stolle D and Hooghe M (2011) Shifting inequalities. Patterns of exclusion and inclusion in emerging forms of political participation. European Societies 13(1): 119-142.

Tarrow S (1996) Social movements in contentious politics: A review article. American Political Science Review 90(4): 874-883.

Teorell J, Charron N, Samanni M, et al. (2009) The Quality of Government Dataset, version 17 June 2009. Göteborg: The Quality of Government Institute, University of Gothenburg. Available at: http://www. qog.pol.gu.se

Thiem A and Dusa A (2012) Introducing the QCA package: A market analysis and software review. Qualitative and Multi-Method Research 10(2): 45-49.

Tilley J and Heath A (2007) The decline of British national pride. The British Journal of Sociology 58(4): 661-678.

Tilly C (1978) From Mobilization to Revolution. New York: Random House.

Tiryakian EA (2004) Introduction: Comparative perspectives on ethnicity and ethnic conflicts. International Journal of Comparative Sociology 45(3-4): 147-159.

Toft M (1996) The geography of ethnic conflict: Do settlement patterns matter? Paper presented at the Annual Meeting of the Midwest Political Science Association, Chicago, IL, 18-20 April.

Toft M (2001) A Theory of Territory, Indivisibility, and Ethnic War. Unpublished Paper. Harvard University, Cambridge, MA.

Toft M (2003) The Geography of Ethnic Violence: Identity, Interests, and the Indivisibility of Territory. Princeton, NJ: Princeton University Press.

Vis B (2012) The comparative advantages of fsQCA and regression analysis for moderately large-N analyses. Sociological Methods \& Research 41(1): 168-198.

Walter B (2006) Building reputation: Why governments fights some separatists but not others. American Journal of Political Science 50(2): 313-330.

Ward MD, Greenhill BD and Bakke KM (2010) The perils of policy by p-value: Predicting civil conflicts. Journal of Peace Research 47(4): 363-375.

Ware RB and Kisriew E (2009) Dagestan: Russian hegemony and Islamic resistance in the North Caucasus. Armonk, NY; London, UK: M.E. Sharpe. 
Weber M ([1922] 1978) Economy and Society, vol. 2. Berkeley, CA: University of California Press.

Weidmann NB (2009) Geography as motivation and opportunity: Group concentration and ethnic conflict. Journal of Conflict Resolution 53(4): 526-543.

Weidmann NB, Rød JK and Cederman L-E (2010) Representing ethnic groups in space: A new dataset. Journal of Peace Research 47(4): 491-499.

\section{Appendix I}

Table 4. Data sources and calibration of outcome and conditions.

Ethnopolitical protest

Source: Minorities at Risk (MAR), variable: PROT

Data for 199|-2003

Missing values: CBH, MBH, SBH: 199I; RGG: 1996, 1997; AM, SM, RM: 1991, 1992

Mode: 2; Median: 2; Mean: 1.57

Categories in original dataset:

0 . No protest

I. Verbal opposition (public letters, petitions, posters, publications, agitation, etc.)

2. Symbolic resistance (scattered acts of symbolic resistance (sit-ins, blockage of traffic, sabotage, and symbolic destruction of property)

3. Small demonstrations (demonstrations, rallies, strikes, and/or riots $<10,000$ )

4. Medium demonstrations (demonstrations, rallies, strikes, and/or riots $<100,000$ )

5. Large demonstrations (mass demonstrations, rallies, strikes, and/or riots, total participation $>100,000$ )

Fuzzy-set calibration syntax in fs/QCA software: calibrate(protest,3,I.5,0.5)

Brief elaboration of calibration: 'protest' is calibrated in such a way that 0 means 'fully out of the set of strong protest' and I means 'fully in the set of strong protest'. For each case, we use the mean protest score for the period 199I-2003 and we establish the crossover point at the value of I.5 (between verbal opposition and symbolic resistance). A mean protest score of 1.5 implies that in our I3-year period, ethnic groups rarely surpass the border of symbolic protest which is considered to be the softer and the least intense version of ethnopolitical protest. We consider mean scores below 0.5 fully out of the set of strong protest and mean scores above 3 fully in the set of strong protest.

Democracy level

Source: Quality of Government (Q०G), variable Democracy (Freedom House/Imputed Polity, 'fh_ipolity2') Data for: 199|-2003

Missing values: CBH, MBH, SBH: 199I; RGG: 1996, 1997; AM, SM, RM: 199I, 1992

Mode: 9.58; Median: 7.17; Mean: 6.63

From QoG codebook:

Scale ranges from 0 to 10, where 0 is least democratic and 10 most democratic. Average of Freedom House (fh_pr and fh_cl) is transformed to a scale $0-10$ and Polity (P_polity2) is transformed to a scale $0-10$. These variables are averaged into fh_polity2. The imputed version has imputed values for countries where data on Polity is missing by regressing Polity on the average Freedom House measure. Hadenius \& Teorell (2005) show that this average index performs better both in terms of validity and reliability than its constituent parts.

Fuzzy-set calibration syntax in fs/QCA software: calibrate(demscore,9.5,7,2)

Brief elaboration of calibration: this condition is calibrated in such a way that 0 means 'fully out of the set of established democracies' and I means 'fully in the set of established democracies'. Following the guidelines established by the Polity project, the threshold value of 7 is established to separate strong democracies from emerging democracies (Jaggers and Gurr 1995: p. 479). All cases with a mean score of 2 or lower are seen as fully out of the set and with a mean score of 9.5 or higher as fully in the set of strong democracies. 
Table 4. (Continued)

Ethnic fractionalization

Source: Quality of Government (Q०G), variable 'Ethnic fractionalization' ('fe_etfra')

Data for: | $991-2003$

Missing values: -

Mode: 0.68I; Median: 0.490; Mean: 0.429

From QoG codebook:

Restricting attention to groups that had at least I percent of country population in the 1990s, Fearon identifies 822 ethnic and 'ethnoreligious' groups in 160 countries. This variable reflects the probability that two randomly selected people from a given country will belong to different such groups. The variable thus ranges from 0 (perfectly homogeneous) to I (highly fragmented).

Fuzzy-set calibration syntax in fs/QCA software: calibrate(ethfract, $0.8,0.495,0$ )

Brief elaboration of calibration: this condition is calibrated in such a way that 0 means 'fully out of the set of ethnically fractionalized societies' and I means 'fully in the set of ethnically fractionalized societies'. We use a cutoff point of .495 , meaning that societies where the probability of belonging to different ethnic groups is higher than $50 \%$ are considered ethnically fractionalized. We avoid using 0.5 as crossover point to make sure that countries with the score 0.5 (Spain) fall out of the analysis. As in our sample the highest degree of ethnic fractionalization is 0.80 (Serbia \& Montenegro), we set the threshold for full set membership at 0.80 . The threshold for being fully out of the set of ethnically fractionalized countries is 0 .

Territorial concentration

Source: Minorities at Risk (MAR), variable: GROUPCON

Data for $|99|-2003$

Missing values: CBH, MBH, SBH: 1991; RGG: 1996, 1997; AM, SM, RM: 1991, 1992

Mode: 3; Median: 2; Mean: 2.18

Categories in original dataset:

0 . Widely dispersed

I. Primarily urban or minority in one region

2. Majority in one region, others dispersed

3. Concentrated in one region

Fuzzy-set calibration syntax in fs/QCA software: calibrate(groupcon,3,I.25,0)

Brief elaboration of calibration: this condition is calibrated in such a way that 0 means 'fully out of the set of geographically concentrated minority groups' and I means 'fully in the set of geographically concentrated minority groups'. We consider groups that fall in categories 0 and I as essentially not concentrated, and those in categories 2 and 3 as essentially concentrated. Because groups that fall in category I are already reasonably concentrated, we place the crossover point (I.25) closer to I than to 2. This gives groups in category I a fuzzy-set score of 0.35 and groups in category 2 a fuzzy-set score of 0.78 .

Political discrimination

Source: Minorities at Risk (MAR), variable: POLDIS

Data for |99|-2003

Missing values: CBH, MBH, SBH: 1991; RGG: 1996, 1997; AM, SM, RM: 199I, 1992

Mode: 0; Median: 0; Mean: 0.80

Categories in original dataset:

0 . No political discrimination

I. Neglect/remedial policies

Due to historical neglect there is substantial underrepresentation in political offices.

There are public policies aimed at improving this underrepresentation)

2. Neglect/no remedial policies

Due to historical neglect there is substantial underrepresentation in political offices. There are no public policies aimed at improving this underrepresentation,

3. Social exclusion/neutral policy 
Table 4. (Continued)

Substantial social practices undermining the group access in political and social arena. There are inadequate policies to offset the discrimination practices.

4. Exclusion/repressive policy

Group is heavily restricted in terms of political participation. No remedial policies.

Fuzzy-set calibration syntax in fs/QCA software: calibrate(poldis,3,0.75,0)

Brief elaboration of calibration: this condition is calibrated in such a way that 0 means 'fully out of the set of strong political discrimination' and I means 'fully in the set of strong political discrimination'. For each case, we use the mean protest score for the period I99I-2003 and we group all cases with at least some form of discrimination in the set of discriminated groups. We thus establish the crossover point at the value 0.75 to ensure that all cases with a score of I are clearly in the set politically discriminated minority groups (fuzzy-set score of .58).

National pride

Source: European Value Survey, indicator ' $\mathrm{g} 006$ '

Question in survey: How proud are you of being [nationality of country]?

Data for years: 1993-1999 (first wave) + 2000-2004 (second wave)

Missing values: Wave I - GA, SIT, TIT, GMD, SMD, IUK, SUK; Wave 2 - LAZ, RAZ, PBE, RBE, TBG, RBG, REE, RGG, RLT, HRO, CRU

Mode: N/A; Median: I.86; Mean: 1.79

Categories in original dataset:

0 . Not at all proud

I. Not proud

2. Quite proud

3. Very proud

The 29 groups were identified based on the following criteria: declared ethnicity (x05I), language spoken at home ( $\mathrm{gOI}$ ), and the region within the country where the interview was conducted (x048).

Fuzzy-set calibration syntax in fs/QCA software: calibrate(pride, $2.5,1.5,0.5$ )

Brief elaboration of calibration: this condition is calibrated in such a way that 0 means 'fully out of the set of strong national pride' and I means 'fully in the set of strong national pride'. The national pride values are coded for each ethnic group present in our sample based on the responses given by individuals with those declared ethnicities. Answer categories range from "Not at all proud' (score of 0 ) to 'Very proud' (score 3). The cutoff membership score is assigned to a pride value of 1.5 , which is a cross-border score between the negative and positive pride feelings. An overall mean score of 2.5 is regarded by the fuzzy scale as (fully in $=1$ ) while a value of 0.5 as (fully out $=0$ ). 


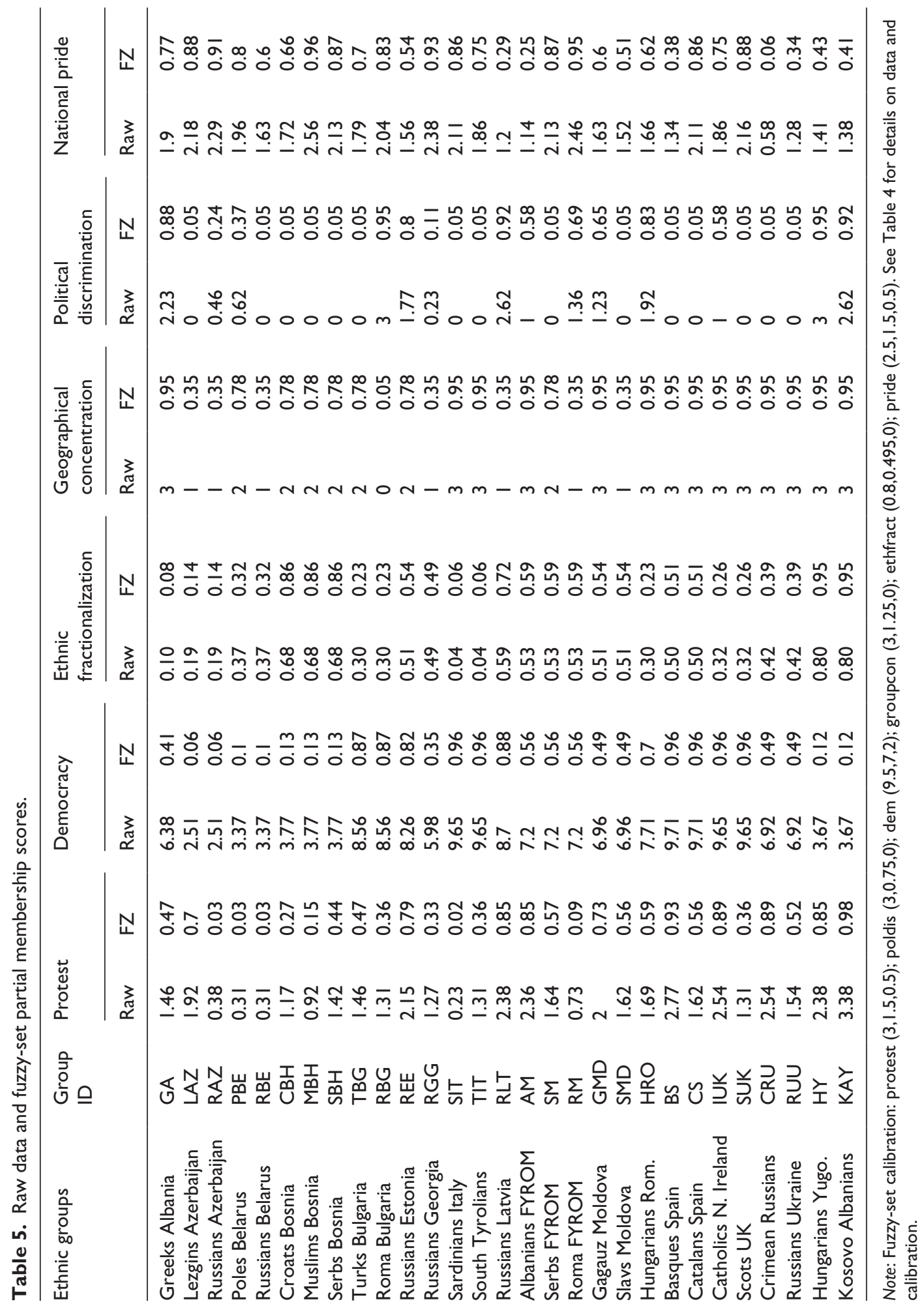




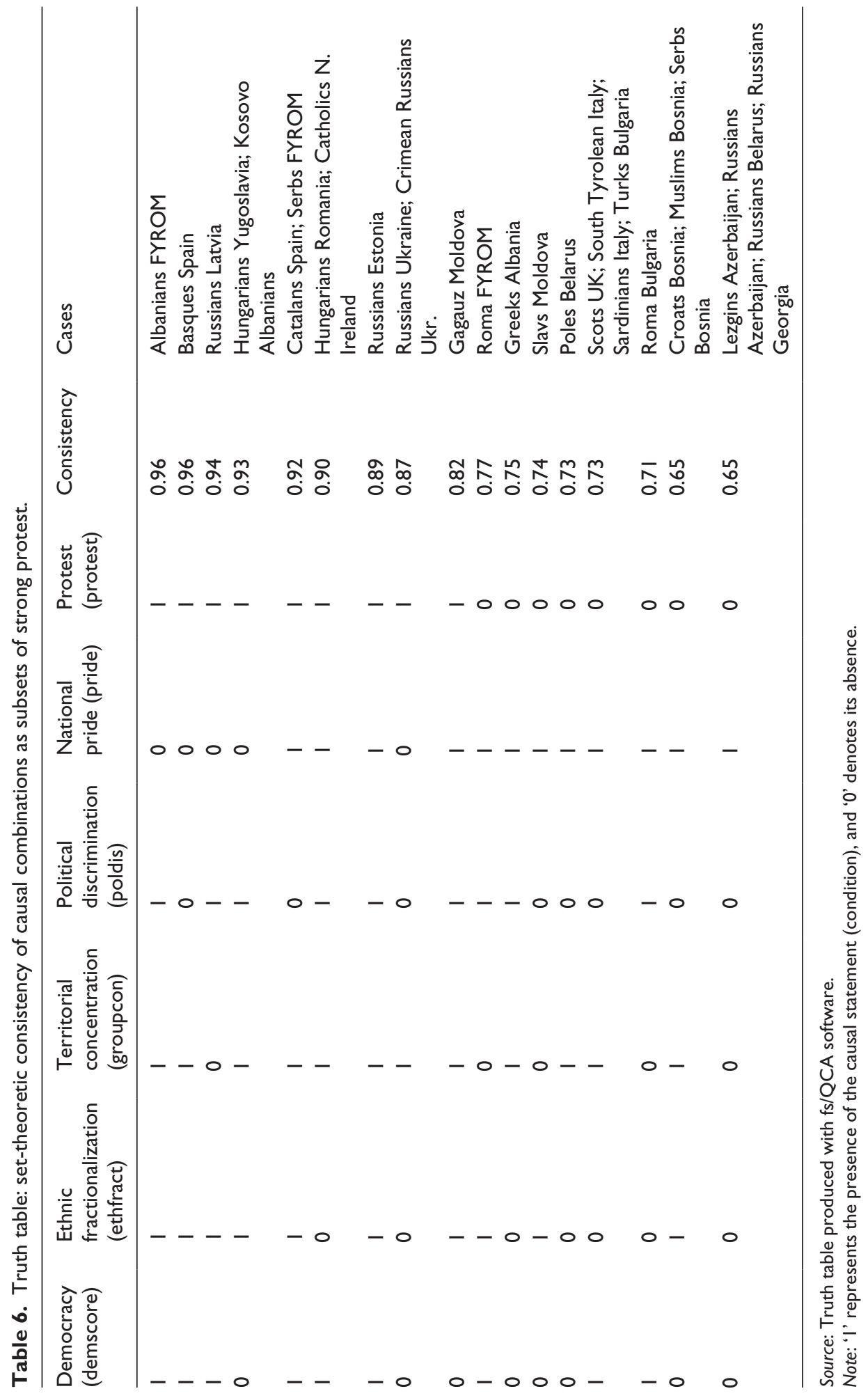




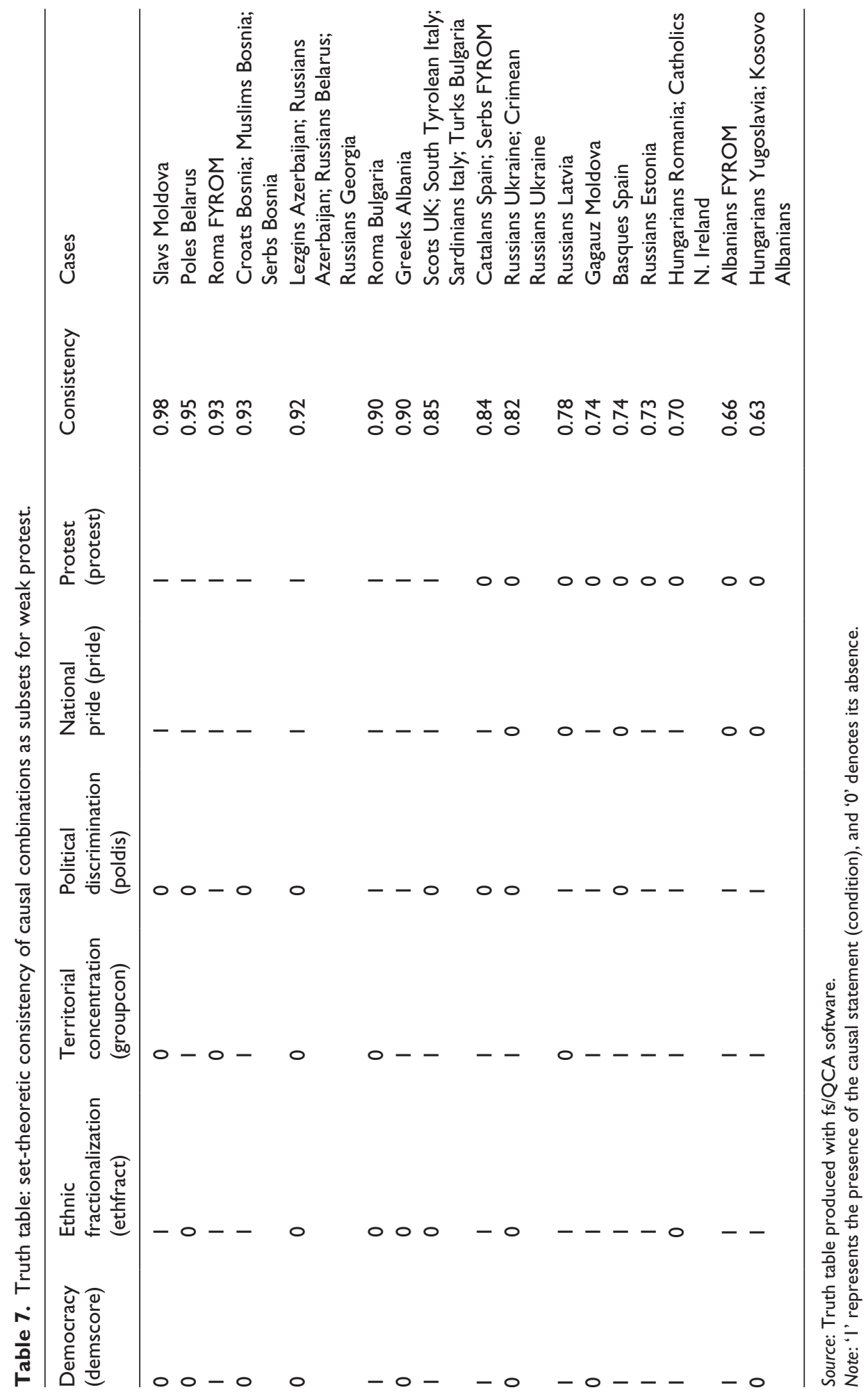

